\title{
CAPITAL SOCIAL, CULTURA E CIDADANIA: uma experiência de projeto de extensão universitária com alunos de Comunicação Social da Universidade Veiga de Almeida
}

\author{
Capital stock, culture and citizenship: \\ An experience of university extension project with students of \\ Social Communication of Veiga de Almeida University
}

Sônia Grácia Pucci Medina ${ }^{1}$

\section{Resumo}

O trabalho visa a oferecer uma referência para o desenvolvimento de projetos intradisciplinares e extradisciplinares em cursos de Comunicação Social, bem como um modelo do que foi executado nos anos de 2004, na Universidade Veiga de Almeida, tendo como objetivos gerais a promoção simultaneamente, a pesquisa básica, o ensino da comunicação e a realização de atividades culturais e de extensão, visando ao desenvolvimento humano e social da comunidade acadêmica e das comunidades próximas à universidade e de interesse do estudo.

Palavras-chave: Desenvolvimento humano; Capital social; Comunicação social.

\section{Abstract}

The work aims to offer a reference for the development of projects intradisciplinares and to extradiscipline in courses of Social Communication, well as a model of what it was executed in the years of 2004 in the University Fertile Valley of Almeida, having as general objective the promotion simultaneously, the basic research, the teaching of the communication and the accomplishment of cultural activities and extension, aiming at the human and social development of the academic community and the communities next to the university and of interest to the study.

Keywords: Human development; Capital stock; Social communication.

\footnotetext{
Mestre em Comunicação Social, tendo como área de pesquisa Comunicação e Cultura. Desenvolveu dissertação sobre Educação como produto da Comunicação; professora do Centro Universitário da Cidade e da Universidade Veiga de Almeida, pesquisadora do NIP - Núcleo Interdisciplinar de Pesquisa, pesquisa sobre as Novas Tecnologias da Comunicação como interferência na educação; psicanalista clínica e professora de psicanálise nas disciplinas de Psicodinâmica das Neuroses e Semiologia Psicanalítica na Sociedade Psicanalítica Ortodoxa do Brasil. Tutora do curso de Metodologia Científica do Núcleo de ensino a distância da Universidade Veiga de Almeida. Autora de dois livros publicados pela Editora Qualitymark nos anos de 2004 e 2005 , respectivamente, Educação Corporativa: teoria e prática e Educação a distância. No prelo, para lançamento em março/2007, o livro Incongruências: uma nova forma de ensinar no século XXI, consultora da P\&P em Jogos Empresariais. sonia@soniapucci.com Site: www.soniapucci.com
} 


\section{Introdução}

As sociedades contemporâneas passam por profundas transformações nas relações econômicas, políticas, tecnológicas, culturais e epistemológicas. Estas transformações estão relacionadas simultaneamente às formas de pensamento, aos meios de comunicação e às práticas das sociedades no que se refere à produção material e simbólica. Frente a estas transformações, coloca-se cada vez mais a necessidade de interagir saberes e práticas visando a intervenções efetivas nos processos sociais.

Para tanto, o curso de Comunicação Social da Universidade Veiga de Almeida (UVA) inseriu em sua matriz curricular a disciplina Projeto de Capital Social, visando à efetiva participação universitária nos processos sociais e culturais.

As disciplinas, saberes, teorias, práticas, métodos, ciências e instrumentais da Comunicação aparecem neste contexto como um campo de saber capaz de aportar padrões relacionais de pensamento, conhecimento, modos de vida e produção social.

Entre os objetivos específicos estão a elaboração de pesquisas originais, o planejamento e confecção de materiais pedagógicos e de divulgação bem como a melhoria das condições de formação de comunicadores sociais, incluindo a melhoria geral das condições de ensinoaprendizagem e de extensão universitária no curso de Comunicação Social da Universidade Veiga de Almeida. Criar um banco de projetos de extensão universitária no curso de Comunicação Social.

O trabalho do projeto estrutura-se sobre as idéias de relação e interação. No que diz respeito aos fenômenos e problemas, serão privilegiadas as abordagens inter e transdisciplinares.

As relações pedagógicas e de trabalho em equipe deverão estar pautadas pelo diálogo, pela cooperação e pela interatividade. O trabalho se fundamentou na leitura e resenha do livro "Capital Social", de Maria Celina D’Araujo. Os membros do projeto são os alunos das cadeiras de Projeto de Capital Social e Estudos Avançados de Marketing do curso de Comunicação Social. O gerenciamento é de responsabilidade da professora mestra Sônia Grácia Pucci Medina.

O projeto utilizou de recursos materiais e humanos, bibliotecas, laboratórios e equipamentos disponíveis da UVA, durante o período letivo de aula. O único financiamento foi em forma de xerox dos materiais produzidos pelos alunos. O quadro abaixo elucida a metodologia utilizada para o desenvolvimento da disciplina.

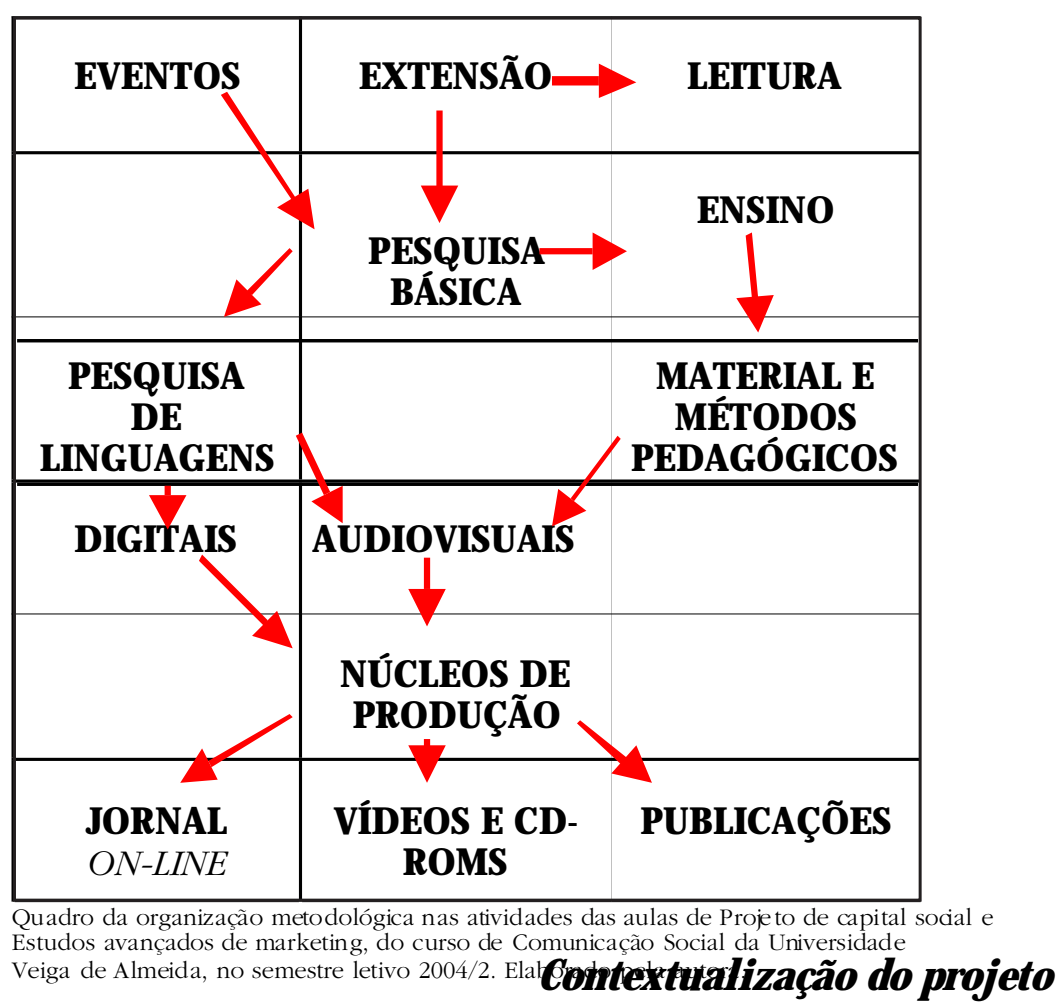


Segundo D’Araújo (2003), "uma sociedade cuja cultura pratica e valoriza a confiança interpessoal é mais propícia a produzir o bem comum, a prosperar". O brasileiro já tem, como uma "norma velada", a solidariedade entre seu povo, desta forma, ao estudar e resenhar o livro Capital Social, os alunos foram embarcando e dando significado para estas normas que, em algumas regiões do país, não possui mais seus significantes.

O conceito de capital social não é novo, mas a partir de estudos de Robert Putnam, publicado em 1993, com o título: Comunidade e democracia: A experiência da Itália moderna, é que o tema tomou notoriedade e, a partir de 1990, o Banco Mundial, segundo D`Araújo (2003):

Passou a distinguir, na avaliação de projetos de desenvolvimento, quatro formas de capital: capital natural, que são os recursos naturais de que é dotado um país; capital financeiro, aquele produzido pela sociedade e que se expressa em infra-estrutura, bens de capital, capital financeiro, imobiliário, entre outros; capital humano, definido pelos graus de saúde, educação e nutrição de um povo; e finalmente, capital social, que expressa, basicamente, a capacidade de uma sociedade de estabelecer laços de confiança interpessoal e redes de cooperação com vistas à produção de bens coletivos. Segundo o Banco, capital social refere-se às instituições, relações e normas sociais que dão qualidade às relações interpessoais em uma dada sociedade.

O projeto de Extensão Universitária do curso de Comunicação Social da UVA tomou o conceito de Capital Social como sendo o alicerce que mantém as instituições em contato entre si e as vincula ao cidadão, visando à produção do bem comum. A partir desses estudos, os alunos se dividiram em quatro grupos, de acordo com a região de moradia.

O grupo da Baixada Fluminense trabalhou a comunidade do Éden da cidade de São João de Meriti; o grupo da Zona Sul, a comunidade de Santa Zita, localizada no antigo Largo da Barra da Tijuca; o grupo da Barra da Tijuca trabalhou a comunidade do Terreirão, antigo Canal das Tachas, e o grupo da Zona Norte trabalhou a Associação Aliança dos Cegos, no bairro São Francisco de Assis.

Os alunos que trabalharam a
Comunidade de Santa Zita iniciaram escolhendo um texto do livro que refletisse o pensamento do grupo "[...] capital social, não é um instrumento que opera solitariamente. Reflete uma maneira integrada de agir e de interagir que tem na confiança e na cooperação as moedas da boa sociedade" (D’ARAUJO, 2003); a partir deste conceito foi embasado o projeto RECICLANDO VIDAS

Santa Zita é uma comunidade onde residem 27 famílias em pequenas casas aglomeradas, cortadas por vielas e com um pátio interno comum. A média de crianças por família é de 3 a 4, desta forma a comunidade tem cerca de 100 crianças, mas também tem jovens e idosos. Localizada em um ponto "nobre" da Barra da Tijuca, o antigo Largo da Barra, em seu redor imensos casarões violentam a pobreza da comunidade que se serve dos parcos salários que são pagos às mulheres que trabalham com limpeza doméstica. Mas a comunidade de Santa Zita tem um traço diferente, ela é alegre e sua alegria contagia a todos que chegam. A música, o assobio, os gritos da criançada é um marco de referência dessa dualidade.

O início do trabalho se deu com uma visita na comunidade no mês de agosto de 2004, quando os alunos foram recebidos pela coordenadora Dona Fátima, que fez todos os relatos sobre a organização da comunidade, quem são os seus moradores, e o que precisam; diante desses dados, os alunos fizeram uma lista de prioridades e concluíram que para Santa Zita, o tema Lixo e Reciclagem poderia aumentar a renda das famílias, bem como conscientizar as crianças da importância do lixo. O grupo passa a estudar sobre Reciclagem de Lixo. Usaram vários materiais da biblioteca, de sites, entre outros, até a produção final da cartilha Reciclando Vidas, que contém: editorial, coluna sobre reciclagem, saúde, economia, culinária e segurança. Experimentaram todas as receitas e aprenderam a trabalhar com sabonetes artesanais.

No dia 28 de novembro de 2004, às $14 \mathrm{~h}$, no pátio interno da comunidade, foi realizado um bate-papo e uma oficina de reciclagem artesanal a respeito da reciclagem do lixo, reaproveitamento de cascas de legumes, vegetais e frutas. Os primeiros a chegarem foram as crianças, que vinham com as cadeiras, logo após as mulheres e os homens, quase toda a comunidade estava presente. A nutricionista convidada, Ana Lúcia, mãe 
da aluna Lidiane, ressaltou a importância da boa alimentação desde a infância. Após o bate-papo, onde as perguntas eram feitas pelas crianças e pelos adultos, e esclarecidos com eficiência pelas alunas Karenina e Cláudia, passou-se para a oficina de artesanato, a cargo das alunas Débora e Clarice. Com habilidade, paciência e dedicação, elas ensinaram a fazer sabonete com frutas, legumes e vegetais, possibilitando o início de novos negócios para contribuir com a renda familiar.

Às 18h, foram encerrados os trabalhos com uma observação interessante feita pelo aluno Fabiano: "as mulheres da comunidade possuem uma grande habilidade manual, bem como um senso empreendedor”. Dona Fátima preparou um almoço para o grupo e com muita alegria preparou o pátio para a realização do evento, e, segundo ela, "precisamos que vocês venham mais vezes aqui, queremos aprender mais".

Em São João de Meriti, na Comunidade

do Éden, o texto trabalhado foi: "[...] capital social está definido por três fatores inter-relacionados: confiança, normas e cadeias de reciprocidade e sistemas de participação cívica, sistemas que permitem às pessoas cooperar, ajudar-se mutuamente, zelar pelo bem público, promover a prosperidade" (D’ARAUJO, 2003). A partir deste conceito, foi embasado o projeto FAÇA DO LIXO UMA ARTE, realizado no dia 13 de novembro de 2004, na Igreja Nossa Senhora do Éden, a partir das $13 \mathrm{~h}$. A rádio comunitária local, bem como cartazes e faixa, no largo, convidavam os moradores para: Palestra da turma de jornalismo da UVA, "faça do Lixo uma Arte" e aprenda a não desperdiçar os alimentos, concorrendo a sorteios de brindes reciclados.

Durante vários dias do mês de setembro de 2004, foram realizadas reuniões na comunidade do Éden, com a colaboração do padre responsável pela igreja Nossa Senhora das Graças. O evento se deu no salão de festas da igreja, com palestra proferida pelas alunas Eloá e Nathália, sobre como reciclar lixo e dele fazer arte. Os alunos distribuíram o Jornal UVALEU, redigido pelo grupo, após estudos e pesquisas para a elaboração das matérias, bem como a experimentação das receitas.

Dia 12 de novembro, um dia antes do evento, iniciam-se os preparativos para as oficinas de culinária e artesanato. Foram convidadas as mães das alunas: Tunísia, Eloá e Janne para ensinar os alunos a fazerem as receitas e os artesanatos, e a aluna Nathália ofereceu sua casa para a realização das oficinas.

No dia do evento, às 14h, Eloá deu uma palestra, utilizando transparências, sobre a importância da reciclagem e o que é o lixo. Em seguida, a aluna Nathália deu as dicas de como fazer as receitas que estavam prontas, que foram oferecidas aos participantes. Estavam presentes aproximadamente 180 pessoas, entre mulheres e crianças do bairro. O detalhe curioso é que todos levaram papel e lápis para as anotações, preocupadas em não perderem nada da fala das alunas. Os participantes iam fazendo diversas perguntas e todo o grupo respondia com objetividade e clareza.

O evento foi encerrado por volta das 18h00, com a degustação de todas as receitas, bem como o sorteio dos brindes, que eram todos reciclados e feitos pelo grupo. Dona Amélia, moradora do bairro, disse: "agora eu já posso fazer xarope para minha tosse que não me deixava dormir, com as cascas de abacaxi que jogava no lixo".

O Terreirão é um bairro com aproximadamente 1.000 moradores, que se enroscam em casebres ao longo do Canal das Tachas no Bairro Recreio dos Bandeirantes, zona oeste da cidade do Rio de Janeiro. Uma comunidade que pode ser considerada miserável, em função de algumas características feitas por meio da observação: desnutrição, criminalidade e sujeira. Embasados pela leitura de Maria Celina, que diz:

[...] captar essas mudanças, entender suas razões e interpretar seus possíveis reflexos sobre a democracia tem sido o objetivo principal do World Values Survey, projeto de pesquisa mundial sobre valores, [...] capital social é assim um conceito tentador para dois mundos, cada um com sua ordem de problemas: o mundo da pobreza e da fome e o mundo das virtudes do desenvolvimento e democracia. (D’ARAÚJO, 2003).

A partir deste conceito, foi-se buscar uma comunidade para desenvolver o projeto, a procura durou todo o mês de agosto e setembro de 2004 e a comunidade eleita foi a do Terreirão. O grupo de alunos desenvolveu uma pesquisa para verificar o que a comunidade sabia sobre Lixo e Reciclagem. 
Passam a estudar como desenvolver uma pesquisa sobre o tema proposto em uma comunidade muito carente. Foram feitas leituras de textos sobre o assunto, além da montagem do questionário, com 3 perguntas sobre: "Você já ouviu falar em reciclagem do lixo?"; "Quer aprender?"; "Como melhorar a qualidade de vida no Terreirão?".

Não houve visita prévia, apenas agendada uma data para a realização da pesquisa: dia 4 de dezembro de 2004, com início às 9h. O grande grupo foi dividido em três subgrupos, que iniciaram a caminhada por entre um amontoado de casas, vielas, pátios e iam interpelando os moradores.

O grupo, formado por estudantes de jornalismo, decidiu montar um panfleto em branco e preto com desenhos sobre sujeira e limpeza e no verso dicas sobre reciclagem e saúde. O primeiro subgrupo ficou com as crianças, o segundo com as mulheres e o terceiro com os homens. Não houve seleção, o processo foi da abordagem informal. As crianças logo aderiram à proposta, que era de colorir o panfleto enquanto os alunos contavam histórias sobre os problemas que o lixo causa à saúde.

O segundo subgrupo, que abordou as mulheres, também teve muito sucesso, pois elas queriam aprender sobre como fazer para melhorar a saúde das crianças. O subgrupo responsável pela abordagem aos homens encontrou muita resistência e reclamação, "de que nada se faz por aqui", segundo um morador, enquanto o outro interpelou dizendo: "Se a gente limpar o canal, como vamos catar a sujeira para vender?" e uma moradora disse que "a Comlurb já veio falar de reciclagem, mas não voltou mais”.

O grupo da disciplina Estudos Avançados de Marketing decidiu trabalhar A Associação Aliança dos Cegos, entidade que abriga 75 cegos na faixa etária acima dos 50 anos. Fica localizada no bairro de São Francisco Xavier, na Rua 24 de Maio, 47, na cidade do Rio de Janeiro. Sua principal fonte de renda é a fabricação de vassouras e rodinhos.

Após a discussão sobre Capital Social, o grupo estabelece o seguinte trecho para contextualizar o projeto:
[...] deve continuar sendo um estímulo para os desafios práticos e teóricos quer do aprimoramento democrático, quer do desenvolvimento. Ao que tudo indica, é uma ferramenta cujo nome pode ser reinventado, mas que continuará entre nós, despertando as mesmas indagações que inquietaram Hume, Tocqueville e Putnam nos séculos XVIII, XIX e XX. (D’ARAUJO, 2003).

Os alunos fizeram várias visitas na Associação Aliança dos Cegos, em grupos diferentes, durante todo o mês de agosto de 2004. Foram recebidos pelo Sr. Edmar, secretário da Associação. O primeiro apelo era o pagamento de dívida contraída junto ao INSS por falha nas administrações passadas, o que culminou com o leilão do prédio que abriga a associação. Mas para os alunos de Comunicação Social este não era o apelo de maior relevância. $\mathrm{Na}$ continuidade da busca de dados, verificouse a necessidade da criação de um planejamento estratégico para a venda das vassouras. "A produção, que pode chegar até 5.000 vassouras/ mês, hoje não atinge 1.000", segundo o morador Sr. Valente, tesoureiro da casa, pois a matériaprima é vendida a um custo muito elevado e a associação não possui pontos de venda.

O principal objetivo passa a ser a elaboração de um planejamento estratégico para a fabricação e venda dos produtos e como objetivos secundários a divulgação da Associação Aliança dos Cegos, por meio de pintura do prédio, placa indicativa, recuperação do jardim e criação de um site, além de sensibilizar a mídia e a comunidade onde estão inseridos.

O grupo foi dividido em subgrupos de acordo com as redes de contatos de cada aluno e os objetivos foram todos alcançados. O fornecedor da matéria-prima irá fornecer a um preço acessível a piaçava e uma rede de supermercados irá comprar toda a produção/ mês. Desta forma, a casa consegue autonomia em sua gestão. Foi possível visitar o vereador Paulo Cerri, que recebeu os alunos no dia 26 de novembro, às 18h, na Câmara dos Vereadores do Rio de Janeiro. A proposta feita ao vereador é da indicação de um advogado para oferecer assessoria gratuita na associação, para que esta possa parcelar e quitar a dívida existente com o INSS. 
O contato com as rádios: Tupi, no programa Show do Pedro Augusto; Rádio CBN, Loureiro Neto e equipe da Rádio Globo; Programa Francisco José, da Rádio Globo, noticiaram o trabalho de extensão universitária, lembrando os antigos projetos como Câmpus Avançado e Projeto Rondon. Foi realizada uma entrevista no programa do Francisco José,na qual se abordou o que é o trabalho de Extensão universitária do curso de Comunicação Social da UVA e a Associação Aliança dos Cegos. O Jornal O Globo, de domingo, dia 26 de setembro de 2004, caderno da Zona Norte, traz uma matéria sobre a Associação, bem como o Jornal O Globo, de terça-feira, dia 05 de outubro de 2004. O Jornal do Brasil, de segunda-feira, dia 20 de dezembro de 2004, página A14, divulga o projeto com depoimento dos alunos e moradores da casa.

A recuperação do prédio, bem como toda a comunicação visual, ficou sob a responsabilidade dos alunos Sergio e Genoir, que levaram um engenheiro e uma arquiteta até o local para fazerem o levantamento do material e mão-de-obra necessária para a recuperação do prédio, bem como do jardim. A partir de então, os grupos foram captar amigos na comunidade para doarem a tinta, pincel, entre outros materiais, recuperação do jardim com novas mudas, poda das arvores, além do contato com a Set Rio, Detran e DNER para colocação de sinalização adequada no local. Os alunos Sérgio e Rodrigo desenvolveram a criação do layout para a placa, bem como conseguiram patrocínio.

O evento aconteceu no dia 18 de dezembro de 2004, a partir das 9h, na Associação Aliança dos Cegos. Repórteres do Jornal do Brasil estavam presentes e fizeram a cobertura. Foi entregue o planejamento, as tabelas de preços, apresentado o fornecedor e o supermercado que vai comprar a produção. Os alunos promoveram um churrasco para a comunidade e os moradores da associação simbolizaram o pensamento de que o Estado, a sociedade e o governo têm funções definidas, mas podem atuar em conjunto, de forma congruente e sinergética. Por volta das 18h, foi concluído o projeto, tendo como conclusão o seguinte pensamento: "capital social nos remete a valores que vão além do racionalismo econômico e talvez por isso gere tanto descontentamento entre os metodólogos que não conseguem medi-lo com a mesma precisão com que se calcula a queda ou a alta de uma bolsa de valores" (D’ARAUJO, 2003).

\section{Considerações finais}

Uma das propostas conclusivas do grupo que trabalhou na Comunidade de Santa Zita foi a de que: "no mundo de hoje, encontramos duas realidades: de um lado, um mundo desenvolvido, de economia estável, e, de outro, um mundo subdesenvolvido, onde uma sociedade precisa de ajuda externa para se estabilizar. Em muitos lugares, realidades diferentes são vizinhas, este é o caso da comunidade Santa Zita”. O grupo da Comunidade do Éden concluiu com um pedido da comunidade para que aconteçam mais dias como este e destacaram dois assuntos de interesse: saúde e direito do cidadão. O grupo da Comunidade do Terreirão concluiu que a comunidade precisa de uma ação conjunta de associações, instituições, ONGs e órgãos municipais instalados no bairro Recreio dos Bandeirantes. A aluna Bianca desabafa: "aqui eles precisam de tudo".

\section{Sugestões}

1) A disciplina deve ser repensada de forma a dar continuidade aos projetos iniciados, as comunidades despertam o desejo de "querer mais" e esta é uma das propostas iniciais do projeto. 2) A necessidade de uma estrutura mínima para suprir gastos com locomoção dos alunos. 3) A interação da comunidade por meio de líderes para fazerem o link entre a universidade e a comunidade. 4) O trabalho conjunto dos professores envolvidos na disciplina/projeto de capital social para que todos desenvolvam a mesma técnica de estudos em sala de aula. O objetivo é levar o aluno à leitura do livro e dos artigos necessários para o entendimento do assunto, desdobrado da seguinte maneira: todos os alunos lêem um artigo oferecido pelo professor e fazem uma resenha. Esta resenha é redistribuída na próxima aula por grupos, os quais fazem uma nova leitura e desenvolvem uma conclusão. Os grupos apresentam, na aula seguinte, o entendimento do texto, bem como um cronograma de atividades, com as propostas de projetos de capital social, em seguida estes grupos determinam as comunidades que irão ser trabalhadas durante o semestre. 
Referências

D’ARAuJO, Maria Celina. Capital social. Rio de Janeiro: Jorge Zahar, 2003.

\section{Bibliografia complementar}

BOFF, Leonardo. Tempo de transcendência: $O$ ser humano como um projeto infinito. Rio de Janeiro: Sextante, 2000.

FUKUYAMA, Francis. Confiança: as virtudes sociais e a criação da prosperidade. Rio de Janeiro: Rocco, 1996.

A grande ruptura: a natureza humana e a reconstituição da ordem social. Rio de Janeiro: Rocco, 2000.
LARA, Xico. Trabalho, educação, cidadania. Rio de Janeiro: Mauad, 2003.

MORIN, Edgar. Os sete saberes necessários à educação do futuro. 10. ed. São Paulo: Cortez, 2000.

PUTNAM, Robert. Comunidade e democracia: a experiência da Itália moderna. Rio de Janeiro: FGV, 1998.

SINGER, Paul. Globalização e desemprego: diagnóstico e alternativas. São Paulo: Contexto, 1998.

TOCQueville, Aléxis de. Democracia na América: várias edições. Belo Horizonte: Itatiaia, 1962; 1987; 1998. 